РОЛЬ ПЛАЦЕНТАРНОГО ФАКТОРА РОСТА ЧЕЛОВЕКА (РІGF) В ДИАГНОСТИКЕ ПРЕЭКЛАМПСИИ.

Егорова Карина Андреевна

\author{
Чувашский государственный университет им. И.Н.Ульянова \\ e-mail: karina.egorova2015@yandex.ru
}

Плацентарный фактор роста (PIGF - placenta growth factor) представляет собой гликопротеин с информацией. А также, это соотношение нужно для использования в качестве помощи для молекулярной массой 46-50 кDa, который вырабатывается эндотелиоцитами сосудов. Он относится к семейству сосудисто-эндотелиального фактора роста (VEGF - vascular endothelial growth factor) и является одним из важнейших регуляторов формирования плаценты и васкуляризации ее ворсин. Плацентарный фактор роста человека (PIGF) особенно синтезируется плацентой в первые недели беременности. Для соотношения sFIt-1/PIGF нужно пользоваться тестом PIGF совместно с тестом sFIt-1. И соотношение sFIt-1/PIGF нужно в качестве помощника во время диагностики преэклампсии вместе с другой диагностической и клинической краткосрочного прогнозирования преэклампсии у беременных женщин, которые находятся с подозрением на преэклампсию совместно с прочей диагностической и клинической информацией. В настоящее время преэклампсия остается одной из основных причин смертности и тяжелой материнской заболеваемости. Преэклампсия- это болезнь, с которой медицинские работники должны знать, как бороться и принимать меры. Сложность его этиологии является сложной задачей и требует дальнейших исследований для его полного понимания.

Ключевые слова: плацентарный фактор роста, преэклампсия, причины преэклампсии.

\title{
THE ROLE OF PLACENTAL GROWTH FACTOR (PIGF) IN DIAGNOSTICS OF PREECLAMPSIA.
}

Egorova Karina Andreevna

\author{
I.N.Ulyanov Chuvash State University \\ e-mail:karina.egorova2015@yandex.ru
}

\begin{abstract}
Placental growth factor (PIGF - placenta growth factor) is a glycoprotein with a molecular weight of 46-50 kDa, which is produced by vascular endothelial cells. It belongs to the family of vascular endothelial growth factor (VEGF - vascular endothelial growth factor) and is one of the most important regulators of the formation of the placenta and vascularization of its villi. Human placental growth factor (PIGF) is especially synthesized by the placenta in the first weeks of pregnancy. For the sFlt-1 / PIGF ratio, you need to use the PIGF test together with the sFlt-1 test. And the sFlt-1 / PIGF ratio is needed as an assistant during the diagnosis of preeclampsia along with other diagnostic and clinical information. And also, this ratio is necessary for use as an aid for short-term prediction of pre-eclampsia in pregnant women who are suspected of preeclampsia with other diagnostic and clinical information. At present, preeclampsia remains one of the main causes of mortality and severe maternal morbidity. Pre-eclampsia is a disease that medical professionals need to know how to deal with and take action. The complexity of its etiology is challenging and requires further research to fully understand it.
\end{abstract}

Keywords: placenta growth factor, preeclampsia, causes of preeclampsia 


\section{Введение}

Заболевание, которое нам сегодня известно,как преэклампсия (ПЭ), впервые было описано Гиппократом около 400 лет до н.э. Преэклампсия понималась как болезнь, которая характеризуется головными болями и судорожными припадками, характерными для поздней беременности, и которая заканчивалась во время родов. Методы лечения данной патологии в основном состояли в том, чтобы привести в баланс внутренние жидкости организма через изменение диеты и кровопускание. С тех пор и вплоть до второй половины 20-го века, достижения в понимании этиологии преэклампсии были достаточно ограничены, несмотря на многочисленные исследования данного заболевания [2].

Преэклампсия занимает третье место в мировом рейтинге причин материнской заболеваемости и смертности [5]. В анализе, проведенном Всемирной организацией здравоохранения, в котором оценивались причины материнской смертности, на втором месте находятся гипертонические причины, встречающиеся в $14 \%$ случаев, которым предшествовали только геморрагические причины, ответственные за 27,1\% материнской смертности [6]. Преэклампсия возникает из-за нарушения сосудистого строения плаценты, которые в дальнейшем, обуславливают циркуляцию ангиогенных факторов в материнском кровотоке, и являются причиной системной дисфункции эндотелиальных клеток и микроангиопатии. В результате воздействия эндотелиальных повреждений на почки развивается клубочковый эндотелиоз и протеинурия, при этом, эндотелиальные клетки клубочка набухают и уменьшается количество фенестр в эндотелие клубочков [3].

Цель - изучить обновления о возникновении преэклампсии и роль плацентарного фактора роста человека.

Плацентарный фактор роста (PlGF - placenta growth factor)- это гликопротеин, который вырабатывается эндотелиоцитами сосудов. Он является одним из важнейших регуляторов формирования плаценты и васкуляризации ее ворсин.

Основной функцией является обеспечение ангиогенеза - процесса образования новых сосудов во время эмбрионального развития, восстановительных процессов после различных травм, ишемических болезней сердца, тяжелых физических нагрузок. Этот белок стимулирует образование коллатерального кровообращения, активацию боковых сосудов при не длительном нарушении кровотока основных сосудов [1].

Считая, что для обеспечения нормального, обычного течения беременности необходимо нормальное и своевременное функционирование фетоплацентарной системы, то роль PlGF становится ясной. И участвуя в процессах регуляции на этапе образования плаценты, он 
обеспечивает полноценное существование системы мать-плацента-плод [4]. При нормально протекающей беременности продукция PlGF начинается с 8-10-й недели гестации и характеризуется резким ее увеличением, которая достигает своих самых высоких значений к 28-30-й неделе беременности, а потом с небольшим снижением данного показателя. У женщин с различными патологиями в течении периода гестации в 92,5\% случаев может встретиться нарушение продукции PlGF с самого начала беременности, которое характеризуется достоверно более низкими значениями ее показателей за период всего времени гестации, при отсутствии крутого подъема кривой ее нарастания в течение III триместра и выраженной вершиной максимальных значений к 28-й неделе. В мировом акушерстве имеются ряд нерешенных проблем, к важнейшим относится преэклампсия (ПЭ) - это заболевание является причиной смертности почти 100 тыс. женщин-матерей в мире ежегодно. В последние годы частота встречаемости преэклампсии в России возросла с 16 до 20,6\%, что, конечно, связано с увеличением числа беременных с тяжелыми экстрагенитальными заболеваниями и осложнениями беременности [5].

Гипертензивные расстройства при беременности связаны с понижением уровня PlGF(плацентарного фактора роста человека) в 4 раза по сравнению со здоровыми беременными женщинами-пациентками. Степень тяжести и осложнений этих нарушений обратно пропорциональна уровню PlGF в крови беременных. При гипертензивных расстройствах, сопровождающихся фетоплацентарной недостаточностью и задержкой внутриутробного развития плода, концентрация белка PIGF минимальна[3]. Аномалия плаценты, как известно, является основной причиной для возникновения преэклампсии, и ее удаление способствует излечению. Из-за аномальной имплантации и плацентации в обедненную сосудами матку, происходит снижение плацентарной перфузии, что приводит к развитию окислительного стресса, состояния гипоксии и освобождения некоторых антиангиогенных факторов. Эти антиангиогенные факторы приводят к генерализованной эндотелиальной дисфункции, которая ответственна за возникновение гипертензионный синдрома и микроангиопатии. Гистологическое исследование последов от женщин с тяжелой преэклампсией выявило некоторые нарушения, такие как инфаркты, тромбозы, атероз и хроническое воспаление. Антиангиогенные белки, продуцируемые аномальной плацентой эндоглин (sEng), а растворимый фактор роста эндотелия сосудов рецептора - 1 (sFlt-1), которые индуцируют эндотелиальную дисфункцию путем ингибирования проангиогенных факторов, таких как плацентарный фактор роста (PIGF) и сосудистый эндотелиальный фактор роста (VEGF). Уровень повышения sFlt-1 в материнской крови напрямую зависит от степени тяжести преэклампсии, в противоположность количеству VEGF и PIGF, которые снижены у пациенток с тяжелым течением по сравнению с нормальной беременностью. 
Наиболее выраженные изменения уровня sFlt-1 и PIGF в крови характерны для раннего начала преэклампсии, по сравнению с ее поздним началом[3].

Прогностический маркер преэклампсии - это уровень PlGF в крови 50-100 пг/мл, а критериями задержки внутриутробного развития плода на фоне преэклампсии являются уровень PIGF в крови до 50 пг/мл, сочетание у беременных трех и выше клинических и анамнестических факторов риска, важнейшими из которых являются ожирение, многоплодие и экстрагенитальные заболевания матери. А значимостью прогностического уровня PIGF в крови для преэклампсии, фетоплацентарной недостаточности и задержки внутриутробного развития плода высока и составляет $87,1 \%$ для гестационной гипертензии, которая также составляет $67,7 \%$ [1].

В течение многих лет ученые разных стран искали лабораторный тест, который помогал бы разобраться в сложных клинических ситуациях, как, например, лабораторная поддержка при HELLP-синдроме. В начале 21 века важнейшим прорывом в данной области явилось предположение о том, что главные проявления преэклампсии, такие как, эндотелиальная дисфункция, гипертензия и протеинурия обусловлены циркулирующими в крови ангиогенными белками. Выводы исследований приводят к гипотезе о том, что важное звено патогенеза преэклампсии - дисбаланс между проангиогенными и антиангиогенными факторами, циркулирующими в материнском кровотоке [1]. Прорывом в данном направлении стали результаты, подтверждающие, что содержание sFlt-1 и PlGF в кровотоке матери позволяет прогнозировать развитие беременности в краткосрочном периоде и оценивать динамику заболевания.

Белок sFlt-1 (растворимая fms-подобная тирозинкиназа-1, растворимый фрагмент VEGFрецептора-1) обладает сильным антиангиогенным действием, проявляет свое действие, связывая и ингибируя такие ангиогенные факторы, как плацентарный фактор роста (PIGF) и фактор роста эндотелия сосудов (VEGF) [7]. Нескольким исследовательским группам удалось доказать, что в крови беременных пациенток уже за несколько недель до появления первых клинических симптомов наблюдается значительное повышение концентрации sFlt-1 одновременно со снижением PIGF [4].

\section{Последствия и профилактика преэклампсии}

Диагноз преэклампсии у беременной женщины сопровождается усилиями, включающими возможные острые последствия этих нарушений (тяжелая тромбоцитопения, диссеминированное внутрисосудистое свертывание крови, отслойка плаценты). Однако очень важно также рассмотреть их долгосрочные последствия, которые бывают иногда непоправимыми. После беременности, осложненной преэклампсией, примерно у 20\% женщин в течение семи лет развивается гипертония или микроальбуминурия, и то же самое 
происходит только с 2\% женщин, которые имели беременность без осложнений [5]. Аналогично, риск острого инфаркта миокарда, инсульта и венозной тромбоэмболии значительно выше у женщин с личным анамнезом преэклампсии [7].

А что касается новорожденных, то сложность последствий после преэклампсии заключается в том, что в тот момент, когда риски во внутриматочной среде перевешивают риски внематочной . В этом смысле встречаются такие последствия, как недоношенность и ее различные последствия (острый респираторный синдром, внутрижелудочковые кровоизлияния, сепсис, бронхолегочная дисплазия). Младенец, рожденный от матери с преэклампсией обычно рождается преждевременно до 34 недель. Некоторые исследования уже показали отрицательное влияние на нейрокогнитивное развитие этих детей в первые два года жизни [7].

В конечном счете, матери, которые были повержены преэклампсией, могут помимо раннее перечисленных заболеваний иметь различные психологические последствия, которые включают в себя беспокойство, изоляцию, трудности в грудном вскармливании, депрессивные расстройства и, среди прочего, нарушение репродуктивной способности. Также длительные пребывания в реанимационных отделениях по причине либо самой женщины, либо новорожденного, физические или умственные ограничения могут нарушить естественный порядок связи между матерью и ребенком [9].

Своевременная и точная постановка диагноза преэклампсия, адекватная оценка степени тяжести чрезвычайно важны для будущей матери и младенца, но часто является тяжелой задачей для акушера-гинеколога. «Золотым стандартом» в диагностике преэклампсии остаются гипертония и протеинурия. Бывает, что их появлению предшествуют патологические прибавки веса, отеки, головные боли, боли в области живота. Иногда приходится проводить дифференциальную диагностику между приступом эклампсии и судорогами другого генеза. Но чаще нужно дифференцировать преэклампсию с гипертензионными состояниями, которые имели место до беременности.

В этом контексте многочисленных и разрушительных последствий преэклампсии возникает необходимость ее профилактики. Которое было продемонстрировано мета-анализом, что раннее применение (до 16-й недели беременности) низкодозированного аспирина уменьшает возникновение преэклампсии, особенно в ее более тяжелых формах (до 34 недель) [7]. Недавнее клиническое испытание, в котором участвовали около 2000 беременных женщин, сравнило использование аспирина и плацебо и наблюдало снижение на $62 \%$ В начале преэклампсии в группе, которая ежедневно принимала 150 мг аспирина [10]. Метформин стал мишенью исследований различных групп беременных женщин относительно его 
влияния на риск преэклампсии. Недавно, мета-анализ показал что, сравненный к инсулину, метформин уменьшил риск беременность - наведенной гипертензии в группе в составе гестатионал диабет женщины. С другой стороны, по сравнению с плацебо, метформин не оказал благотворного влияния на преэклампсию [7]. Параллельно, правастатин был указан, как хороший вариант для предотвращения преэклампсии, хотя тщательные исследования доказали, что необходимо сделать с эскалацией дозы для того чтобы подтвердить свою эффективность [10]. Таким образом, обозначена настоятельная необходимость как можно раньше распознать беременную женщину, которая подвержена большему риску появления преэклампсии, в идеале в ее субклинической фазе, чтобы можно было проводить профилактические мероприятия. Подобно тому, что произошло за последние 20 лет с отслеживанием и обнаружением анеуплоидий, в которых прогностические модели применялись в первом триместре гораздо более эффективным способом, в настоящее время проводится поиск эффективного и раннего предиктора преэклампсии в рамках нового предложения по инвертированной пирамиде дородового ухода. Это предложение предполагает, что усилия должны быть сосредоточены в первом триместре, чтобы иметь более ранний диагноз и терапевтические предложения, установленные в субклинических стадиях обострений [7].

\section{Прогнозирование}

Сейчас для определения sFlt-1 и PIGF показателей используются два автоматизированных теста -Elecsys PIGF и Elecsys sFlt-1, которые доступны для повседневных лабораторных исследований; дискриминационное значение для соотношения sFlt-1/PLGF определено как 85. Это дает возможность провести надежную и аналитически правильную границу между здоровыми пациентками и пациентками с преэклампсией на сроках до 34-ой недели беременности. Тесты Elecsys sFlt-1 и PlGF были выпущены в 2009 году с информационным лозунгом «для помощи в диагностике». Дальше команда специалистов обнаружила, что одной из самых неудовлетворенных медицинских потребностей при ведении пациенток, которые находятся в группе риска развития преэклампсии, является кратковременная оценка развития заболевания еще до проявления клинических симптомов[7].

Для того чтобы получить доказательства того, что соотношение Elecsys sFlt-1 / P1GF может быть использовано для кратковременного прогноза преэклампсии, в период с декабря 2010 г. по январь 2014 г. компания «Рош» провела исследование PROGNOSIS (Прогнозирование краткосрочного результата у беременных женщин с подозрением на преэклампсию с помощью ангиогенных биомаркеров sFlt-1 / PIGF). Более 1270 беременных женщины были обследованы в 30 медицинских учреждениях из 14 стран мира. Благодаря этому мультицентровому исследованию было доказано, соотношение sFlt-1/P1GF предназначено 
для использования в качестве помощи в краткосрочном прогнозировании преэклампсии (исключения и включения) у беременных женщин с подозрением на преэклампсию в сочетании с другими диагностическими и клиническими данными. Было также показано, что до 34-й недели беременности при клинически явной преэклампсии беременные, у которых индекс sFlt-1/P1GF был выше 3-й квартили (> 655,2), имели наиболее высокий риск преждевременных родов в краткосрочной перспективе. Через 48 часов только 29,4\% беременных женщин с таким индексом не были родоразрешены, в то время как 50\% пациенток, имевших sFlt-1-P1GF-индекс ниже 3-й квартили, беременность сохраняли [7]. Также благодаря использованию sFlt-1/P1GF-индекса возможна дифференциальная диагностика других форм гипертензионных состояний во время беременности и хронических заболеваний почек в анамнезе.

В Германии при проведении оценки медицинских технологий был поднят вопрос о точности и рентабельности тестов на преэклампсию. Инициаторы проекта установили, что используемые тесты являются относительно недорогими, но, в общем, их качество признается неудовлетворительным. Поэтому для оценки экономического эффекта от включения sFlt-1/PIGF в современную диагностическую практику была разработана экспертно-аналитическая модель. Согласно модельным расчетам, даже если тесты только дополняют стандартную практику, расходы на ведение нормально протекающей беременности снижаются на 40\%. Сокращение средств происходит за счет уменьшения числа ложноотрицательных на 67\%, а ложноположительных результатов - на $71 \%$. Более точная в сравнении с обычной практикой классификация пациенток с риском развития преэклампсии и исключение тех, кто не находится в группе риска сберегает средства системы здравоохранения. Кроме того, ценность новых тестов на преэклампсию заключается в их способности корректно идентифицировать бессимптомное протекание ПЭ и исключить ненужные расходы в случаях, когда ПЭ, вероятнее всего, развиваться не будет [9].

\section{Заключение}

Таким образом, уровень плацентарного фактора роста человека является ранним и ценным маркером при диагностике преэклампсии. Он преднамеревает начальные признаки нарушений в фетоплацентарном комплексе, которые возникают задолго до её клинической плацентарной недостаточности. Своевременная диагностика и проведение прогноза гипертензионного синдрома и фетоплацентарной недостаточности у беременных, которые относятся к группам высокого риска для них это послужит реальным резервом снижения материнской и перинатальной заболеваемости и смертности. А повышение отношения уровня sFIt-1 к уровню PIGF в сыворотке крови является ранним маркером преэклампсии и 
свидетельствует о возможном ее развитии. Величина данного показателя ассоциирована со степенью тяжести преэклампсии.

\section{Список литературы:}

1. Роль плацентарного фактора роста в развитии фетоплацентарной недостаточности при гипертензивных нарушениях в период гестации / Н.А.Шахбазова // Проблемы репродукции. 2014. №1. С. 87-91.

2. Е.В. Козырева, Л.Ю. Давидян, В.В. Кометова, Е.Н. Маланина, А.Ю. Бодасаров, Н.В. Вознесенская // Проблемы репродукции. 2016. №6. С. 58-65.

3. Особенности функционирования системы гомеостаза у беременных с преэклампсией / Курманбаев Т.Е., Яковлев Н.В., Набиуллина Р.М. // Медицина: актуальные вопросы и тенденции развития. 2016.№9. С.2.

4. Галина Т.В. Преэклампсия: резервы улучшения исходов для матери и плода: автореф. дис. канд. мед. наук / Т.В. Галина. - М., 2011. - С. 24.

5. Денисова Т.Г., Васильева Э.Н., Шамитова Е.Н., Ассанский В.Г. Обеспеченность витамином Д пациенток с преэклампсией // Современные проблемы науки и образования, 2015. - № 1.

6. Гульмия Л., Сибай Б. /Материнская смертность от преэклампсии и эклампсии. Семинары в перинатологии // 2012. №36. С.56-59.

7. Инновационные биомаркеры для диагностики и прогноза преэклампсии/ Аверкиева В.С., Лисянская М.В. // Поликлиника. 2016.№ 1-3.С. 20-23.

8. Verlohren S, Herraiz I, et al. The sFlt-1/PIGF ratio in different types of hypertensive pregnancy disorders and its prognostic potential in preeclamptic patients. Am J Obstet Gynecol. 2012; 206 (1): 58.e1-8.

9. Say L., Chou D., Gemmill A. /Global causes of maternal death: a WHO systematic analysis // The Lancet Global Health, 2014. -№2(6).

10. Hadker N., Garg S., et al. Are there financial savings associated with supplementing current diagnostic practice for preeclampsia with a novel test? Learnings from a modeling analysis from a German payer perspective. Hypertens Pregnancy, 2013; 32(2): 105-119. 